\title{
A High-Intensity, RF Plasma-Sputter Negative Ion Source
}

\author{
G. D. Alton, R. Lohwasser, B Cui," Y. Bao," T. Zhang," \\ C. A. Reed \\ Oak Ridge National Laboratory, P. O. Box 2008, Oak Ridge, TN 37831-6368 USA \\ 'China Institute of Atomic Energy, Beijing, China
}

\begin{abstract}
A high-intensity, plasma-sputter negative-ion source based on the use of RF power for plasma generation has been developed that can be operated in either pulsed or $d c$ modes. The source utilizes a high-Q, self-igniting, inductively coupled antenna system, operating at $80 \mathrm{MHz}$ that has been optimized to generate Cs-seeded plasmas at low pressures (typically, $<1 \mathrm{mTorr}$ for Xe). The source is equipped with a $19-\mathrm{mm}$ diameter spherical-sector cathode machined from the desired material. To date, the source has been utilized to generate $d c$ negative-ion beams from a variety of species, including: $\mathrm{C}^{-}(610 \mu \mathrm{A}) ; \mathrm{F}^{-}(100 \mu \mathrm{A}) ; \mathrm{Si}^{-}(500 \mu \mathrm{A}) ; \mathrm{S}^{-}(500 \mu \mathrm{A}) ; \mathrm{P}^{-}(125 \mu \mathrm{A}) ; \mathrm{Cl}^{-}(200 \mu \mathrm{A})$; $\mathrm{Ni}^{-}(150 \mu \mathrm{A}) ; \mathrm{Cu}^{-}(230 \mu \mathrm{A}): \mathrm{Ge}^{-}(125 \mu \mathrm{A}) ; \mathrm{As}^{-}(100 \mu \mathrm{A}) ; \mathrm{Se}^{-}(200 \mu \mathrm{A}) ; \mathrm{Ag}^{-}(70 \mu \mathrm{A}) ; \mathrm{Pt}^{-}(125 \mu \mathrm{A}) ;$ $\mathrm{Au}^{-}(250 \mu \mathrm{A})$. The normalized emittance $\varepsilon_{n}$ of the source at the $80 \%$ contour is: $\varepsilon_{n}=7.5$ mm.mrad. $(\mathrm{MeV})^{1 / 2}$. The design principles of the source, operational parameters, ion optics, emittance and intensities for a number of negative-ion species will be presented in this report.
\end{abstract}

Negative-ion source technology has steadily advanced over the years, in keeping with the continual demand for higher intensity negative ion beams with improved beam qualities for a variety of tandem electrostatic accelerator-based fundamental and applied research as well as low-energy atomic physics research applications. The advancements in this technology have centered about the development of versatile cesium- and plasmasputter negative-ion sources, including those described in Ref. 1 . The tandem accelerator has also either been used [2] or considered for use as an injector for synchrotron heavyion accelerators [3]. The plasma-sputter negative-ion source is well suited for this application in that pulsed negative-ion beam intensities exceeding the practical value of $\sim 200 \mu \mathrm{A}$ (peak intensity) can be delivered to the synchrotron from the tandem electrostatic accelerator for a wide variety of heavy-ion species. It also offers the prospect of use for batch-mode generation of radioactive ion beams for injection into tandem electrostatic accelerators for post acceleration because of the perfect over-lap of the plasma particles that sputter the sample and the area of the sample irradiated by the production beam. In general, the plasma-sputter negative-ion source generates higher beam intensities with improved emittances than their Cs-sputter counterparts. Therefore, several plasma-sputter negative-ion sources have been developed over the past few years

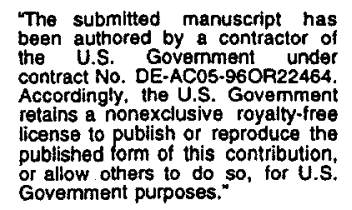




\section{DISCLAIMER}

This report was prepared as an account of work sponsored by an agency of the United States Government. Neither the United States Government nor any agency thereof, nor any of their employees, make any warranty, express or implied, or assumes any legal liability or responsibility for the accuracy, completeness, or usefulness of any information, apparatus, product, or process disclosed, or represents that its use would not infringe privately owned rights. Reference herein to any specific commercial product, process, or service by trade name, trademark, manufacturer, or otherwise does not necessarily constitute or imply its endorsement, recommendation, or favoring by the United States Government or any agency thereof. The views and opinions of authors expressed herein do not necessarily state or reflect those of the United States Government or any agency thereof. 


\section{DISCLAIMER}

Portions of this document may be illegible in electronic image products. Images are produced from the best available original document. 
several plasma-sputter negative-ion sources have been developed over the past few years for a wide variety of applications, including those described in Refs. [4-9]. These sources all utilize hot cathodes for plasma ignition with the exception of the source described in Ref. 9, which uses RF power. Because of the erosional nature of the hot-cathode plasma discharge, cathodic wear limits the lifetimes of sources based on this principle. The use of RF power for plasma ignition, in principle, overcomes this handicap, reduces the complexity of operation and lowers overall source maintenance. For these reasons, we have chosen RF as the means for powering the discharge in the plasma-sputter negativeion source described in the present article. (The studies and developments associated with antenna design and optimization for the source were the central objective of a thesis by one of the present authors [10].)

\section{DESCRIPTION AND DESIGN ASPECTS OF THE SOURCE}

The negative-ion source, displayed schematically in Fig. 1, is based on the use of RF power for plasma-sputter generation of high-intensity negative-ion beams. The source utilizes a high-Q, self-igniting, inductively-coupled antenna system, operating at $80 \mathrm{MHz}$, that has been optimized to generate Cs-seeded plasmas at low pressures (typically, $<1 \mathrm{mTorr}$ for Xe). Figure 2 schematically illustrates the power supply arrangement of the source. The source can be operated in either pulsed or dc modes for the generation of negative ion beams; by simply reversing the polarity high voltage power supply, the source can also be use to generate positive-ion beams in either of the two modes of operation. The source is modular and can be quickly installed-into or removed-from the stainless steel, re-entrant, vacuum chamber, attached to the metal-to-

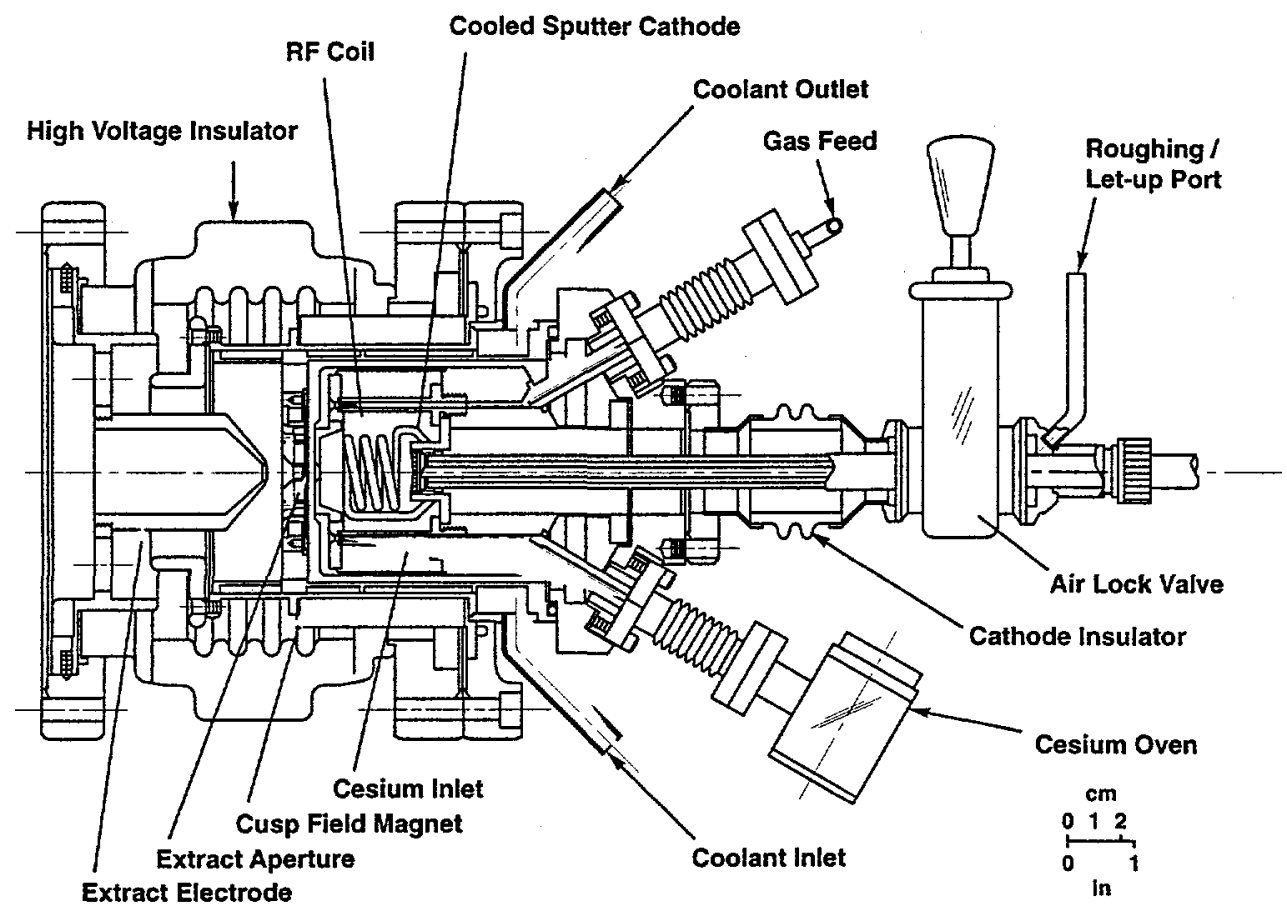

Fig. 1. Schematic Drawing of the RF plasma-sputter negative-ion source. 


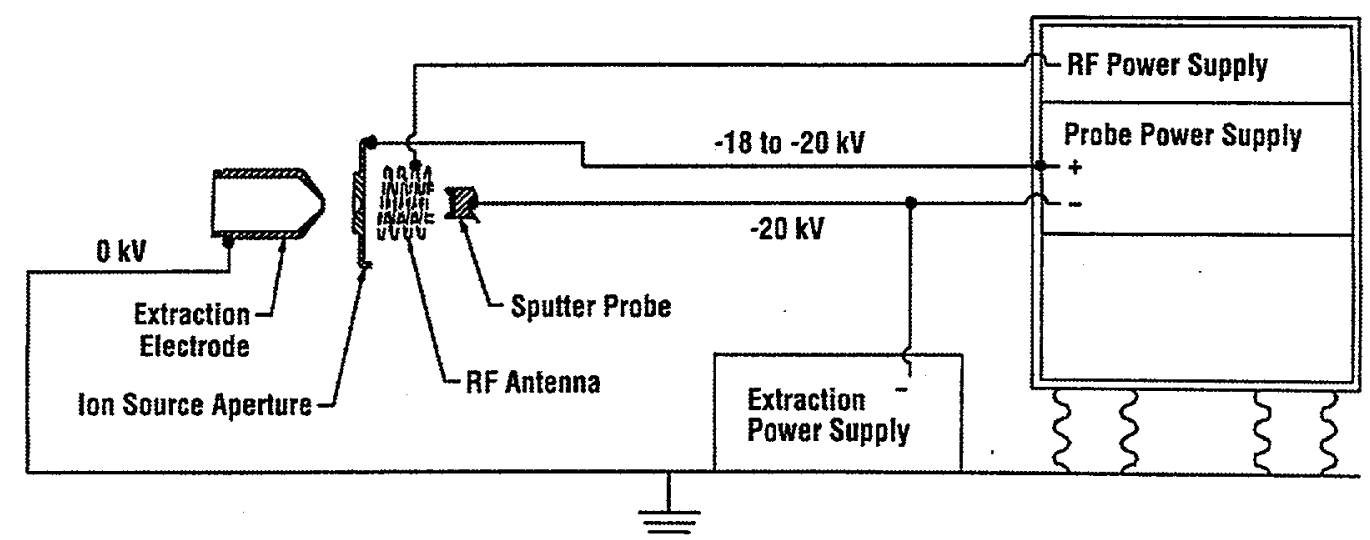

Fig. 2. Schematic drawing of the arrangement of the power supplies for the RF plasma-sputter negative ion source.

ceramic $\left(\mathrm{Al}_{2} \mathrm{O}_{3}\right)$ high voltage insulator. The extraction-electrode system is attached to the ground plane of the high voltage insulator. The main vacuum chamber is equipped with permanent magnets positioned around the periphery of the chamber to form a longitudinal magnetic field (maximum field strength: $380 \mathrm{G}$ ) for confinement of the plasma in the radial direction. The axial magnetic field distribution, shown in Fig. 3, is designed to reach a maximum value at the aperture of the source and to drop off quickly toward the sputter sample position. This magnetic field geometry was conceived to eliminate magnetic field induced non-uniformity effects at the sample surface and to guide the accelerated particles along field lines toward the extraction aperture. This concept is highly successful as evidenced by the uniformity of the sputter patterns on samples that have undergone extensive bombardment in the plasma discharge. The sputter-probe sample can be withdrawn into the vacuum air lock for quick change without having to interrupt the main vacuum in a time period of $\leq 5$ minutes. The following materials are used for various components of the source: (1) modular re-entrant ion source housing: stainless steel; (2) high voltage insulator: stainless steel flanged, metal-to-ceramic $\left(\mathrm{Al}_{2} \mathrm{O}_{3}\right)$ bonded with metal-to-metal seals; (3) sputter sample feed-through: stainlesssteel flanged, metal-to-ceramic $\left(\mathrm{Al}_{2} \mathrm{O}_{3}\right)$ bonded with metal-to-metal seals; (4) filament and $\mathrm{RF}$ feed-through: stainless steel flanged, metal-to-ceramic $\left(\mathrm{Al}_{2} \mathrm{O}_{3}\right)$ bonded with metal-to-metal seals; (5)

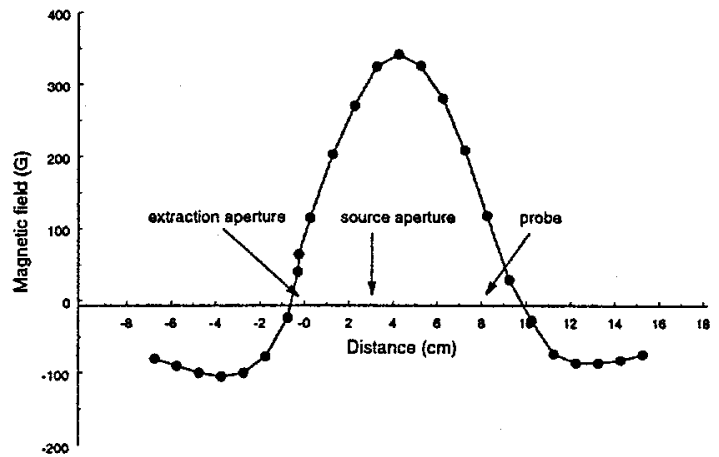

Fig. 3. Axial magnetic field distribution used to confine the plasma in the radial direction. The field is formed with permanent magnets placed around the periphery of the reentrant vacuum housing. internal sputter probe insulator: $\mathrm{BN}$; (6) vacuum/air-lock and isolation valve: stainless steel with elastomer-seals; and (7) $\mathrm{H}_{2} \mathrm{O}$-cooled, sputter sample holder: stainless steel and copper with an elastomer seal. 


\section{Principles of operation}

The sputter negative-ion formation process depends exponentially on the difference between the electron affinity $E_{A}$ of the species of interest and the value of the work function $\phi$ of the surface and, therefore, low work functions are desirable [11]. Cs vapor is very effective in lowering the work functions of surfaces either statically or dynamically [12] and is therefore fed into the Xe supported discharge at a controlled rate. Since the sputtering process continually removes adsorbed materials, the dynamic method continually supplies $\mathrm{Cs}^{\circ}$ to the surface and thus offers a means for providing close to optimum surface work functions. The sample is $\mathrm{H}_{2} \mathrm{O}$ cooled to enhance $\mathrm{Cs}^{\circ}$ condensation on the surface for this purpose. The sputtering process is effected by accelerating $\mathrm{Xe}^{+}$particles extracted from the plasma up to $2 \mathrm{keV}$ in energy where they impinge and uniformly sputter the spherical-sector voltage sputter sample. The interface between the spherical-sector geometry sample and the plasma forms a spherical-geometry lens system that focuses convergent negative-ion beams through a $4.5-\mathrm{mm}$ diameter extraction aperture, located at a distance equal to the radius of curvature $(50 \mathrm{~mm})$ of the sample. This geometry minimizes aberrations, reduces $\mathrm{Cs}^{\circ}$ vapor and $\mathrm{Xe}$ gas flow from the source, and ensures efficient ion extraction from the source.

\section{DESCRIPTION OF THE RF PLASMA GENERATION SYSTEM}

Stable operation of the source at minimal neutral density within the plasma chamber is quintessential for negative-ion-beam generation applications since prohibitive losses can occur during transit through the plasma due to the rather large cross" sections for electron collision-detachment $\left(\sigma \cong 10^{-14}-10^{-16} \mathrm{~cm}^{2}\right)$ at pressures in excess of 10 $m$ Torr [13]. Thus, one of the principal objectives of the project was to design and develop a high- $Q$ antenna system capable of self-ignition and maintenance of low-density plasmas at low operating pressures. These objectives were accomplished (1) by choosing a rather high operating frequency $(80 \mathrm{MHz})$ to effect a higher degree of ionization within a given plasma volume: (2) by designing an inductively coupled, high- $Q$ antenna system and matching circuit for efficient coupling of RF power to the plasma-discharge; and (3) by evaluating the performance of a given antenna in terms of the parameters of selfignited plasmas. A schematic representation of the RF coupling system is shown in Fig. 4.

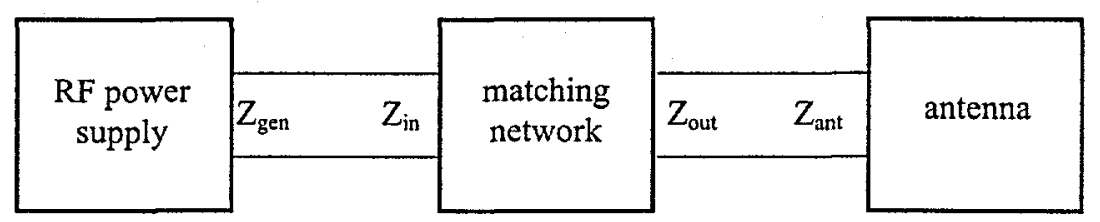

Fig. 4. Schematic representation of the RF coupling system. 


\section{The impedance matching network}

The power $P$ adsorbed by the load or antenna, that in turn, provides the energy to generate and sustain the plasma, can be expressed through the following relation:

$$
P=U^{2} Z_{\text {ant }} /\left(Z_{\text {gen }}+Z_{\text {ant }}\right)^{2}
$$

where $U$ is the voltage of the RF power supply and $Z_{\text {gen }}$ and $Z_{\text {ant }}$ are complex representatives of their respective resistances. The impedances are optimally matched whenever $Z_{\text {gen }}=Z_{\text {ant }}$.

Since the plasma density may vary over several orders of magnitude during startup and operation of the source, this causes an impedance mismatch, thus necessitating the insertion of a tunable impedance matching network between the RF generator and antenna. The function of an impedance matching network is to minimize power transmission losses between two discrete circuits with different impedances. Several schemes have been developed for impedance matching, including the $\pi$-network, illustrated schematically in Fig. 5, chosen for optimizing the coupling of power into the plasma for our applications.

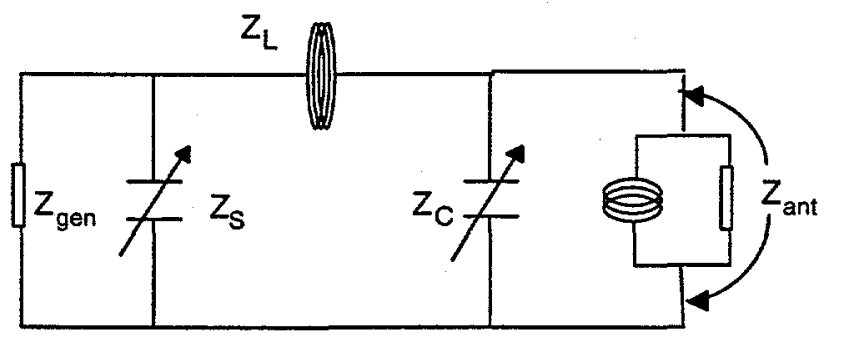

$$
\begin{aligned}
& Z_{\text {gen }} \text { : impedance of RF power supply } \\
& Z_{S} \text { : impedance of source capacitor } \\
& Z_{L}: \text { impedance of inductive coil } \\
& Z_{C}: \text { impedance of load capacitor } \\
& Z_{\text {ant }} \text { : impedance of antenna }
\end{aligned}
$$

Fig. 5. Schematic diagram of the $\pi$-network used to match the impedance of the RF generator to that of the antenna and thereby optimize coupling of the RF power to the plasma.

\section{The antenna design}

The principal objective of this aspect of the project was to develop antennae for efficient coupling of power into plasmas for ion source applications for which spiral geometry antennae are desirable. Spiral antennae were wound from 3-mm diameter $\mathrm{Cu}$ tubing with variable outer diameters and numbers of turns to approximate the specified inductance value for the antenna. The matching network, shown schematically in Fig. 5, was then constructed and close coupled to the ion source. Variable capacitors were used for both $C_{S}(10$ to $77 \mathrm{pF})$ and $C_{c}(100$ to $1000 \mathrm{pF})$ so that the circuit could be tuned to optimal plasma generation conditions to evaluate the effectiveness of a particular antenna design for coupling power into the plasma, as well as to compensate for variations in total capacitance and inductance in the circuit attributable to connecting wires and induced capacitance in a particular antenna. The circuit provided easy tuning over a wide range 
of plasma densities for evaluating a variety of antenna designs. The physical shape, geometry, size, and materials of construction of the antennae and RF feed-through affect the electrical characteristics of the circuit that must be optimized so that it is resonant with the operating frequency of the RF generator. The resonance frequency for an antenna with inductance $L$ and capacitance $C$ is given by the familiar relation

$$
f_{\text {res }}=1 / 2 \pi \sqrt{L C}
$$

Thus, the resonant frequency $f_{r e s}$ of the antenna can be adjusted to agree with the operating frequency $f_{\text {gen }}$ by changing the $L C$ product.

The antennae considered for the plasma sputter negative ion source applications were formed from $3-\mathrm{mm}$ diameter $\mathrm{Cu}$ tubing by varying the diameter, pitch, and number of turns. The use of $\mathrm{Cu}$ tubing permits $\mathrm{H}_{2} \mathrm{O}$ or air cooling of the antennae during operation. The ability to alter the capacitance or inductance of a particular antenna and thereby bring the circuit into resonance with the drive frequency of the generator provides an easy method for optimizing the coupling between the antenna and plasma. For example, the inductance can be varied by changing the number of turns or the diameter of the coils while the capacitance can be varied by changing the pitch of the coils (spacing between coils). The inductances of prospective antennae were calculated by use of the following formula

$$
L(n, r, l) \approx \frac{r^{2} \cdot n^{2}}{16.4 \cdot 10^{6}(9 r+10 l)}
$$

where $n$ is the number of turns and $r$ is the radius of the coil of length $l$.

The various antennae were each evaluated by measuring the densities of their self ignited plasmas by use of a Langmuir probe placed within a vacuum chamber identical in size to that of the application source. Figure 6 displays electron density versus $R F$ power for five antennae wound for different resonant frequencies. The antennae all have the same coil diameter and pitch but different number of turns. As noted, the central antenna is wound so that it is in resonance with the $80 \mathrm{MHz}$ RF generator frequency, thus illustrating the importance of making the resonance frequency, $f_{\text {res }}$, of the combination antenna/feed-through system identical to that of the $R F$ generator, $f_{\text {gen }}$.

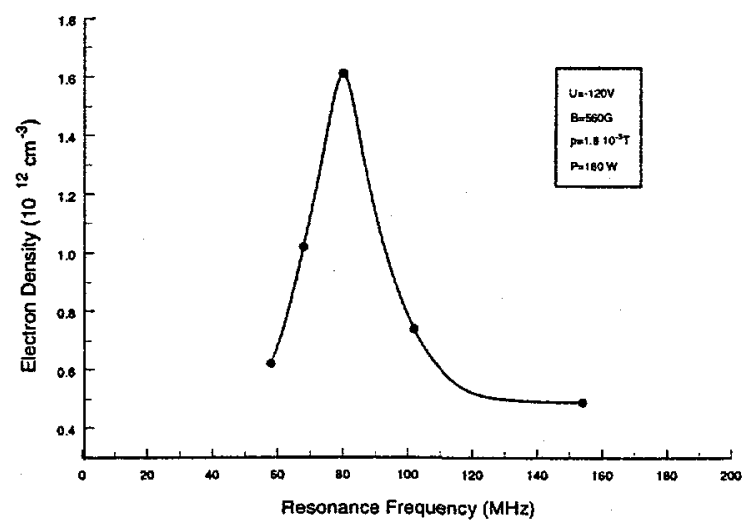

Fig. 6. Electron density versus RF power for five antennae wound with the same radii $r$ but different number of turns $n$. The central antenna is in resonance with the $80 \mathrm{MHz} \mathrm{RF}$ generator.

From these studies, an easy an effective method for designing antennae/feed-through systems was developed. Equations 2 and 3 can be combined to arrive at an expression for the radius $r$ of the antenna in terms 
of its length $l$, number of turns $n$, operating frequency $f_{\text {res }}$ and capacitance $C$ of the feedthrough system given by

$$
r(n, l)=\frac{1.87 \cdot 10^{6}+2.04 \cdot 10^{3} \sqrt{1.68 \cdot 10^{5}+f_{\text {res }}^{2} C n^{2} l}}{f_{\text {res }}^{2} n^{2} \mathrm{C}}
$$

Final tuning of the coil can be effected by adjusting length $l$ and turn-to-turn spacing $d$. The presence of a plasma will cause slight changes in the resonance frequency of the circuit due to changes in the capacitance of the system. This can be compensated for by changing the resonant frequency of the coil to slightly lower values. For the antennae used in these studies, we found that the optimum resonance frequency was 78 $\mathrm{MHz}$.

For plasma-sputter negative-ion source applications, low plasma densities are desirable due to the fact that the negative-ion beam will be greatly attenuated by passage through regions of high plasma density. Also the inner diameter of the coil must be greater than the diameter of the sputter sample. For the source described in this report, the parameters of the optimum coil wound from 3-mm diameter oxygen-free $\mathrm{Cu}$ tubing are: $n: 4 ; r_{c}: 21 \mathrm{~mm} ; \emptyset_{t}(\mathrm{~mm}): 3 ; d_{c}: 7.8 \mathrm{~mm} ; l_{c}: 29 \mathrm{~mm} ; S_{T}: 25.4 \mathrm{~mm}$. The antenna is coated with a thin layer of porcelain to prevent sputtering of the copper coil during operation; the porcelain does not change the characteristics of the antenna and is flexible enough to allow changes in turn-to-turn spacing required for fine tuning to the desired resonant frequency $(80 \mathrm{MHz})$. An isometric drawing of the coil is shown in Fig. 7.

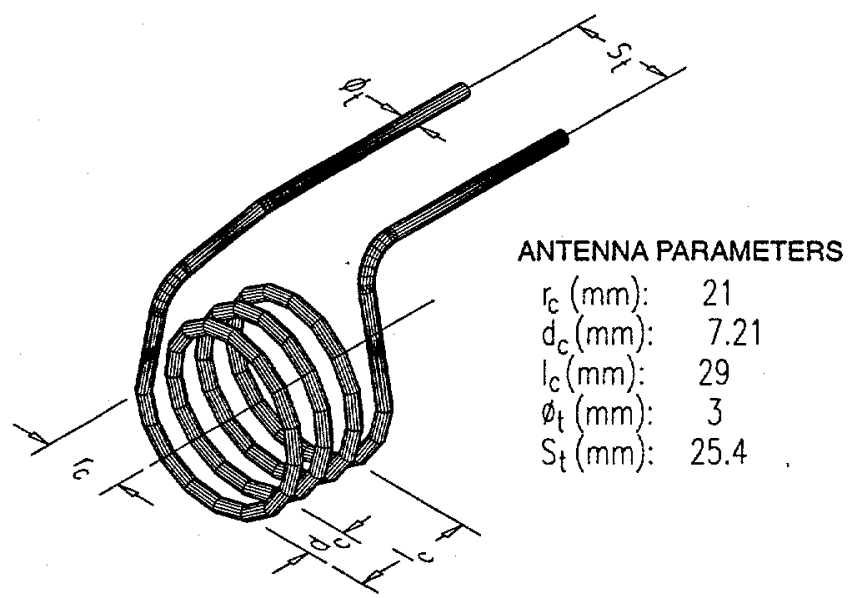

Fig. 7. Isometric of the optimized antenna for the plasma-sputter negative ion source, the parameters for the antenna are: $r_{c}(\mathrm{~mm})=21 ; n=4 ; d_{c}(\mathrm{~mm})=7.25 ; l_{c}(\mathrm{~mm})=29 ; S_{T}(\mathrm{~mm})=25.4 ; \mathscr{\emptyset}_{l}(\mathrm{~mm}): 3$.

\section{OPERATIONAL PARAMETERS}

In order to realize optimum performance of the plasma-sputter negative-ion source, it is necessary to know the dependence of relative or absolute negative ion beam 
intensity on the important operational parameters which include: Cs oven temperature; discharge support gas pressure; $R F$ discharge power; and sputter-probe voltage.

\section{Negative-ion beam intensity versus cesium oven temperature}

The flow of Cs into the source offers a general and dynamic means of lowering the work functions of surfaces and at the same time, a means for overcoming deleterious poisoning effects that may occur due to the presence of certain impurities in the discharge. Since the effective Cs coverage depends on the difference between the rate of arrival and departure of $\mathrm{Cs}$ vapor to and from the sputter probe surface, the value of the work function of the surface and consequently the negative-ion beam intensity is sensitively dependent on $\mathrm{Cs}^{\circ}$-oven temperature [12]. The knowledge of the negative-ion yield or relative negative-ion yield on this parameter is quintessential for optimizing negative-ion yields from the source. Relative negative-ion yield versus $\mathrm{Cs}^{\circ}$-oven temperature, obtained at fixed RF power, Xe support-gas discharge pressure, and sputter sample voltage are displayed in Fig. 8. Once known, the $\mathrm{Cs}^{\circ}$ oven temperature, as a general rule, can be set at a fixed value of $\leqslant T_{\max }$ where $T_{\max } \sim$ $240-245^{\circ} \mathrm{C}$. It also important to note that the $\mathrm{Cs}^{\circ}$ oven temperature cannot be used as a real-time control parameter because of the characteristically slow response times

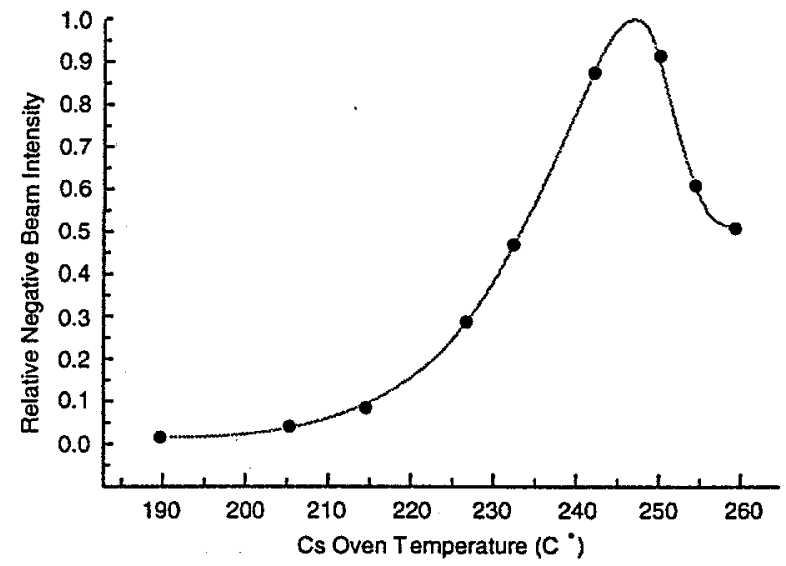

Fig. 8. Relative negative ion beam intensity versus $\mathrm{Cs}^{\circ}$ oven temperature for the RF plasma-sputter negative ion source. Sputter sample: Pt; support gas: Xe; pressure: $1 \times 10^{-5}$ Torr. required for thermal equilibrium processes. Values higher than $T_{\max }$ should be avoided since higher temperatures can be deleterious to the intensity and lead to operational instability due to sparking.

\section{Negative-ion beam intensity versus Xe support-gas pressure}

Stable operation at minimal neutral density within the plasma chamber is quintessential for negative-ion beam generation applications since prohibitive losses can occur during transit through the plasma due to the rather large cross sections $\left(\sigma \sim 10^{-14}\right.$ $-10^{-16} \mathrm{~cm}^{2}$ ) for electron collision-detachment at pressures in excess of $10 \mathrm{mTorr}$ [13]. Thus, one of the principal objectives of the project was to design and develop a high-Q antenna system capable of self-ignition and maintenance of low-density plasmas at low operating pressures as discussed previously. Figure 9 displays negative-ion beam intensity versus externally measured $\mathrm{Xe}$ pressure for fixed $\mathrm{Cs}$ oven temperature, $\mathrm{RF}$ power, and Cs sputter-probe voltage. The pressure in the plasma chamber is $\sim 10$ times these values as measured with a capacitance manometer. For a given support-gas 
species, the collision-detachment cross section depends on the electron affinity of the species as well as the velocity of the particle and thus, the magnitude of detachment loss will, in general, vary from species to species at a given pressure.

\section{Negative-ion beam intensity versus RF power}

Figure 10 illustrates the dependence of negative-ion beam versus RF power for $\mathrm{C}^{-}$. The $\mathrm{RF}$ power required to reach saturation of the negative-ion beam intensity depends on the sample material and source operational parameters used during the experiments. In general, the RF power required to reach maximum negativeion beam intensities for the materials used in this study ranged between 40 and $100 \mathrm{~W}$.

\section{Negative-ion beam intensity versus sputter-probe voltage}

Since the sputter ratio varies from material to material, the probe voltage required to reach steady-state negative-ion beam intensities also varies from species to species. Easily sputtered materials such as $\mathrm{Cu}$ and $\mathrm{Au}$ reach steady state conditions at much lower voltages than does a lower sputtering material such as C. An example of the dependence of negative-ion beam intensity versus sputter-sample voltage for $\mathrm{C}$ is displayed in Fig. 11.

\section{NEGATIVE-ION BEAM INTENSITY AND EMITTANCE DATA}

\section{Negative-ion beam intensity data}

The mass spectra from an Au sample are displayed in Fig. 11. As noted, the spectra are very clean from this species

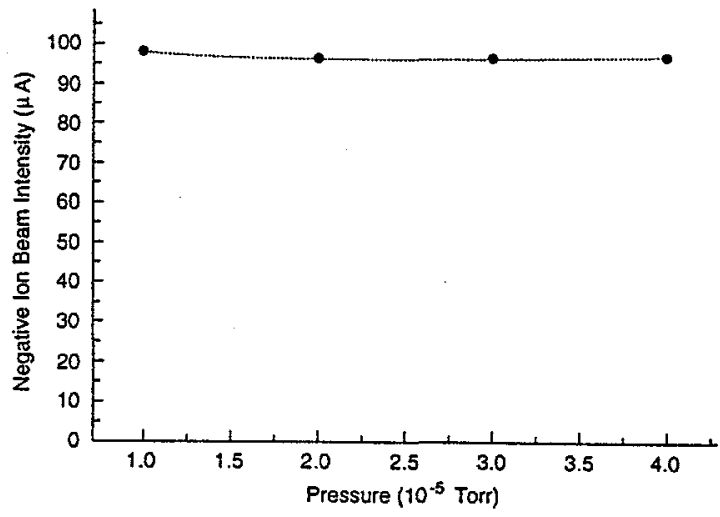

Fig. 9. Negative-ion beam intensity versus Xe external pressure for the RF plasma-sputter negative ion source. Sputter sample: $\mathrm{Au} ; \mathrm{Cs}^{\circ}$-oven temperature: $260^{\circ} \mathrm{C}$.

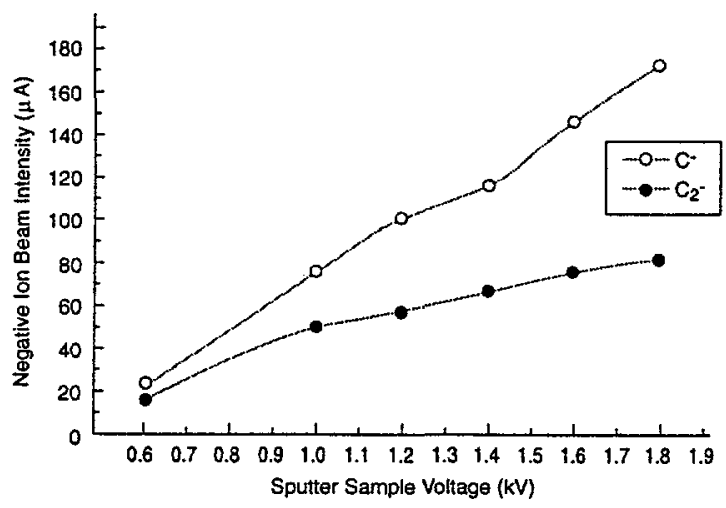

Fig. 10. Relative negative ion beam intensity versus sputter-sample voltage for the RF plasmasputter negative ion source. Sputter sample: C; support gas: $\mathrm{Xe}$; pressure: $1.4 \times 10^{-5}$ Torr; $\mathrm{Cs}^{\circ}$-oven temperature: $200^{\circ} \mathrm{C}$.

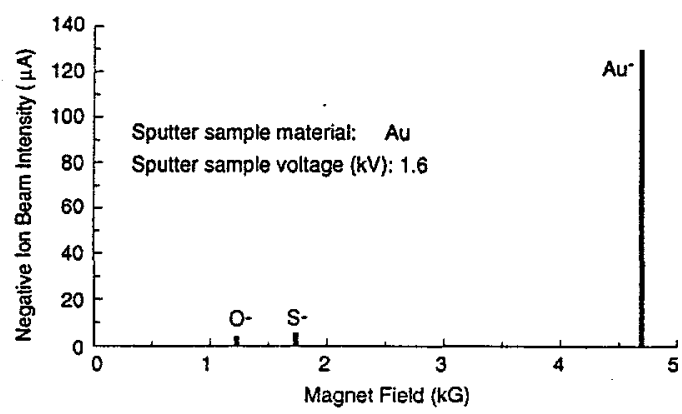

Fig. 11. Mass spectra taken from an Au sputtersample. Sputter-sample voltage: $1.6 \mathrm{kV}$. 
with only low intensities of $\mathrm{O}^{-}$and $\mathrm{S}^{-}$present. To date, the source has been utilized to generate $d c$ negative-ion beams for a variety of species from a $19-\mathrm{mm}$ diameter sphericalsector cathode, including those shown in Table I.

Table I: Negative-ion beam intensity data for the RF plasma sputter negative-ion source.

\begin{tabular}{clc}
$\begin{array}{c}\text { Species } \\
\text { Sputter }\end{array}$ & Probe Material & $\begin{array}{c}\text { Beam Intensity } \\
(\boldsymbol{\mu A})\end{array}$ \\
\hline $\mathrm{C}^{-}$ & $\mathrm{C}$ & 610 \\
$\mathrm{~F}$ & $\mathrm{LiF}$ & 100 \\
$\mathrm{Si}^{-}$ & $\mathrm{Si}$ & 500 \\
$\mathrm{~S}^{-}$ & $\mathrm{ZnS}$ & 500 \\
$\mathrm{P}^{-}$ & $\mathrm{GaP}$ & 125 \\
$\mathrm{Cl}^{-}$ & $\mathrm{NaCl}$ & 200 \\
$\mathrm{Ni}^{-}$ & $\mathrm{Ni}$ & 150 \\
$\mathrm{Cu}^{-}$ & $\mathrm{Cu}$ & 230 \\
$\mathrm{Ge}^{-}$ & $\mathrm{Ge}$ & 125 \\
$\mathrm{Se}^{-}$ & $\mathrm{CdSe}$ & 40 \\
$\mathrm{As}^{-}$ & $\mathrm{GaAs}$ & 100 \\
$\mathrm{Se}^{-}$ & $\mathrm{CdSe}$ & 200 \\
$\mathrm{Ag}^{-}$ & $\mathrm{Ag}$ & 70 \\
$\mathrm{Au}^{-}$ & $\mathrm{Au}$ & 250 \\
$\mathrm{Pt}^{-}$ & $\mathrm{Pt}$ & 125 \\
& & \\
\hline
\end{tabular}

\section{Emittance data}

The emittance of the source was measured using the equipment and procedures described in Refs. 14 and 15. Normalized emittance versus percentage of total negative-ion beam for $200 \mu \mathrm{A} \mathrm{Cu}$ beam is shown in Fig. 12. As noted, the normalized emittance $\varepsilon_{\mathrm{n}}$ for $80 \%$ of the total beam is $\varepsilon_{\mathrm{n}} \sim 7.5 \pi \mathrm{mm} . \mathrm{mrad}(\mathrm{MeV})^{1 / 2}$. In general, the emittances of the source are slightly lower than those measured for Cs-sputter sources even though the intensities from the present source are in general higher for a given species.

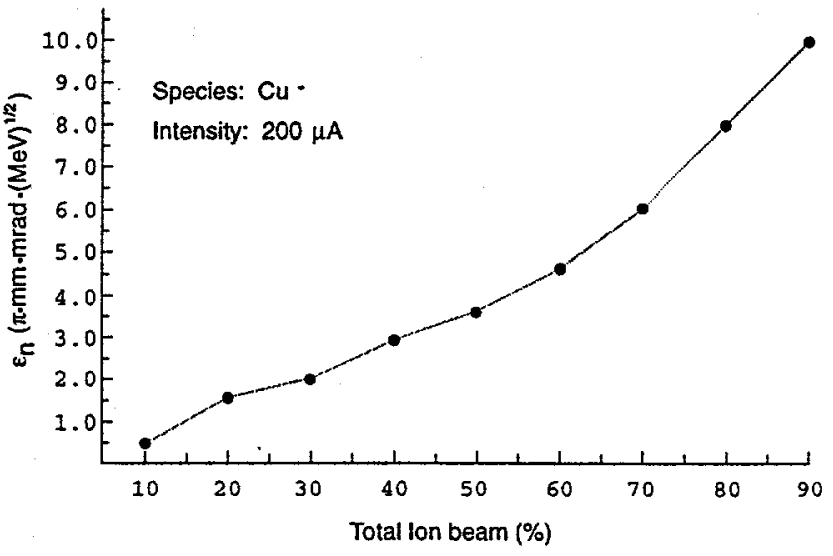

Fig. 12. Normalized emittance $\varepsilon_{n}$ versus percentage of total negative ion beam for the RF plasma-sputter negative ion source. 


\section{ACKNOWLEDGMENTS}

Research at the Oak Ridge National Laboratory is supported by the U.S. Department of Energy under contract DE-AC05-96OR22464 with Lockheed Martin Energy Research Corp.

\section{REFERENCES}

1. . G. D. Alton, Nucl. Instr. and Meth. B 73 (1993) 221.

2. P. Thieberger, M. McKeown and H. E. Wegner, IEEE Trans. Nucl. Sci. NS-30 (4) (1983) 2746.

3. G. D. Alton and C. M. Jones, Nucl. Instr. and Meth. A 244 (1986) 170.

4. H. H. Andersen, IEEE Trans. Nucl. Sci. NS-22 (1975) 1632; P. Tykesson, H. H. Andersen and H. J. Heinemeier, IEEE Trans. Nucl. Sci. NS-23 (1976) 1104.

5. G. D. Alton and G. K. Blazey, Nucl. Instr. and Meth. 166 (1979) 105.

6. G. D. Alton, Y. Mori, A. Takagi, A. Ueno and S. Fukumoto, Nucl. Instr. and Meth. A 270 (1988) 194; Y. Mori, G. D. Alton, A. Takagi, A. Ueno and S. Fukumoto, Nucl. Instr. and Meth. A 273 (1988) 5.

7. Y. Mori, Nucl. Instr. and Meth. A 328 (1993) 146.

8. G. D. Alton, Rev. Sci. Instr. 63 (1992) 2455.

9. J. Ishikawa, H. Tsuji, Y. Okada, Y. Toyota and Y. Gotoh, Vacuum 44 (1993) 203.

10. "High Efficiency RF Plasma Generation Systems for Ion Source Applications," R. Lohwasser, Diplom Thesis, Dept. of Phys. Ludwig Maxmilians Univeristät, München, Germany, June 1997 (unpublished).

11. J. K. Nørskov and B. I. Lundqvist, Phys. Rev. B 19 (1979) 5661.

12. G. D. Alton, Surface Sci. 175 (1986) 226.

13. J. B. Hasted, Physics of Atomic Collisions, $2^{\text {nd }}$ Edition (Elsevier, New York, 1972) Ch. 8.

14. G. D. Alton and J. W. McConnell, Nucl. Instr. and Meth. A 268 (1989) 445.

15. G. D. Alton, and R. W. Sayer, J. Phys. D: Appl. Phys. 22 (1989) 557. 